\title{
Blood Bicarbonate Decreased, CTCAE
}

National Cancer Institute

\section{Source}

National Cancer Institute. Blood Bicarbonate Decreased, CT CAE. NCI Thesaurus. Code C143217.

A finding based on laboratory test results that indicate a decrease in levels of bicarbonate in a venous blood specimen. 